\title{
The Effect of Lean Techniques on Elimination of Waste in Composite Panel Production Using Paired t-test
}

\author{
Pavan Hiremath $^{1}$, S. Narayanan ${ }^{1 *}$ and Manjunath Shettar ${ }^{1}$ \\ ${ }^{1}$ Department of Mechanical and Manufacturing Engineering, Manipal Institute of Technology, \\ Manipal Academy of Higher Education, Manipal-576104, Karnataka, India.
}

\begin{abstract}
A penny saved is a penny earned' as this phrase says it all, the key for increased profit lies in the elimination of non-value adding actions in any production process. This study concentrates mainly on the procedures to identify and to reduce the different types of wastes in a production process. Initially the data related to types of waste and their classification according lean techniques were analyzed and implemented on a production process. The data were recorded for a whole month before implementation and for a whole month after implementation. Later the influence of the lean techniques was analyzed on two different sections of waste, for $5 \%$ significance value using paired t-test. It was found that there is a positive impact of lean techniques on some areas of production flow.
\end{abstract}

\section{Introduction}

There is a phrase, "you can't make something out of nothing." Which means there is s need of resource to produce anything which is small or huge. But, there are only very few instances where the transformation of resource/raw material to finished entity take place effectively, and the rest leads to the creation of Muda (waste). Wastes in a production system may be generated due to using wrong resources, failing to get necessary resources, using a resource in a fruitless way etc. The money invested, time consumed, man power used etc. on these resources also lead to wastes which some time goes unnoticed. In production structure a waste which is created at any stage, will have its effect twice or thrice at the end and leaves the customer and manufacturer dissatisfied.

The main purpose of lean manufacturing technique is to eliminate different wastes which are present in a company through various improvement activities. So, what is waste? It can be in many forms, but the basic idea is to eliminate anything and everything that does not add value in a manufacturing forum. Some forms of wastes are: waiting, is the time taken by a component to proceed for the next process. Transport, is the time taken for unnecessary movements of the raw material. Motion, is the unproductive movements of the people. Over-processing, is more processing of the raw material than required. Excess

\footnotetext{
*Corresponding author: s.narayanan@manipal.edu
} 
inventory, is the quantity of raw material stored than required and the defective part production as well as over production adds up to this list.

\section{Lean techniques for Waste Treatment}

In most of the fabrication or R\&D sectors, the type and quantity of the resource utilized my not be same in each interval of time. In this context this research focuses on a particular family of materials namely, composite panels. To introduce lean concepts anywhere one should know all the corners of it. Identification of type and source of waste holds the top requisite for planning the steps to eliminate it. According to Justyna Rybicka et al. [1] there is a need of classification of waste and arranging them in a specific order. Figure 1 shows the hierarchy of wastes (by looking at this arrangement, one should be able to identify what should be done next) from prevention which is the most desirable (non-waste) scenario, through to waste disposal, which is considered the most wasteful currently known process. Implementation of these ideas to the fabrication area plays a crucial part. There are several challenges faced during the implementation, few among them are stressed in table 1.

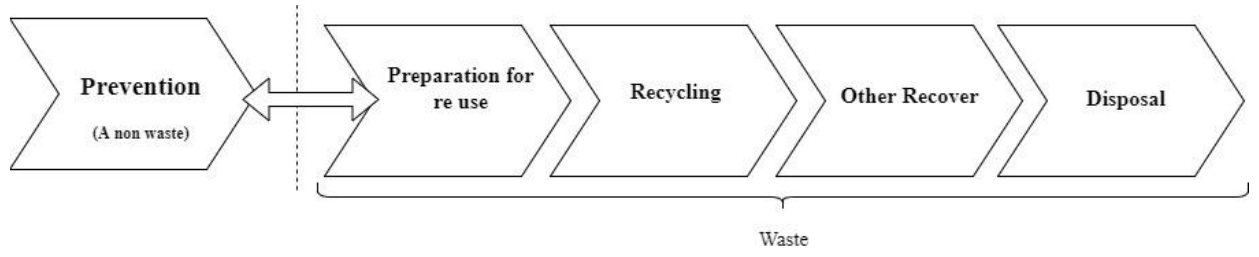

Fig. 1. Waste hierarchy [1].

Table 1. Challenges faced during implementation of lean manufacturing [2].

\begin{tabular}{|l|l|}
\hline Management & $\begin{array}{l}\text { funding, time available, training quality, bonding with labors, size of the } \\
\text { plant, cost of implementation, difficulties in collecting data, job } \\
\text { satisfaction of employees, quality of the labor etc. }\end{array}$ \\
\hline Workers & $\begin{array}{l}\text { Lack of interest, negative attitude, friction for changing the habits, lack } \\
\text { of awareness, negative feedback from colleagues, less skilled labors, lack } \\
\text { of interest in learning, unable to judge the outcomes etc. }\end{array}$ \\
\hline Machinery & $\begin{array}{l}\text { Insufficient machines, poor advanced machinery, insufficient technical } \\
\text { resources etc. }\end{array}$ \\
\hline
\end{tabular}

To overcome the obstacles in implementing lean philosophy to reduce waste, needs recording the flow of the resources (flow mapping) from a supplier till final product's quality assurance. Waste management in the field of production is a quick growing field and it contributes largely by increasing efficiency, economy as well as a systematic approach [3]. Tools such as mapping is widely used for optimization in manufacturing. Mapping representing the present scenario in a well-arranged way. It acts as a bench mark for continuous actives [4]. Process mapping is one of the efficient and convenient way to capture and draft the data related to waste mapping. It allows to identify the material flow path and corners of waste generation in a manufacturing process. The objectives of mapping such as product quality improvement, waste elimination, maintaining inventory under control and operation and financial control [5]. The benefits of IDEF0 (process modelling tool) and MEW (material energy, waste mapping) on manufacturing process improvement and improvement opportunities for economic development through resource 
minimization was described by Bolin and Smith [6]. The tools that have been used for process mapping with intent to outline waste are: value stream mapping, Sankey diagrams, material flow analysis, IDEF0, MEW and flow chats. [7-8].

\section{Identification of wastes in process flow}

With all the available and analyzed data, lean techniques were initially implemented on one segment of a unit to check its significant influence on the reduction of waste. Some of the techniques were; Kanban, just in time production, multi-functional worker and one-piece production. Figure 2 shows the process flow and identified wastes (1 to 12) during each process. Figure 3 shows the variation in time recorded before and after implementation of lean techniques for a month. For other identified wastes $(4,6$ and 11), they were subdivided into different further categories such as waste (consumables) in fiber waste, breather, polyethene bags etc.

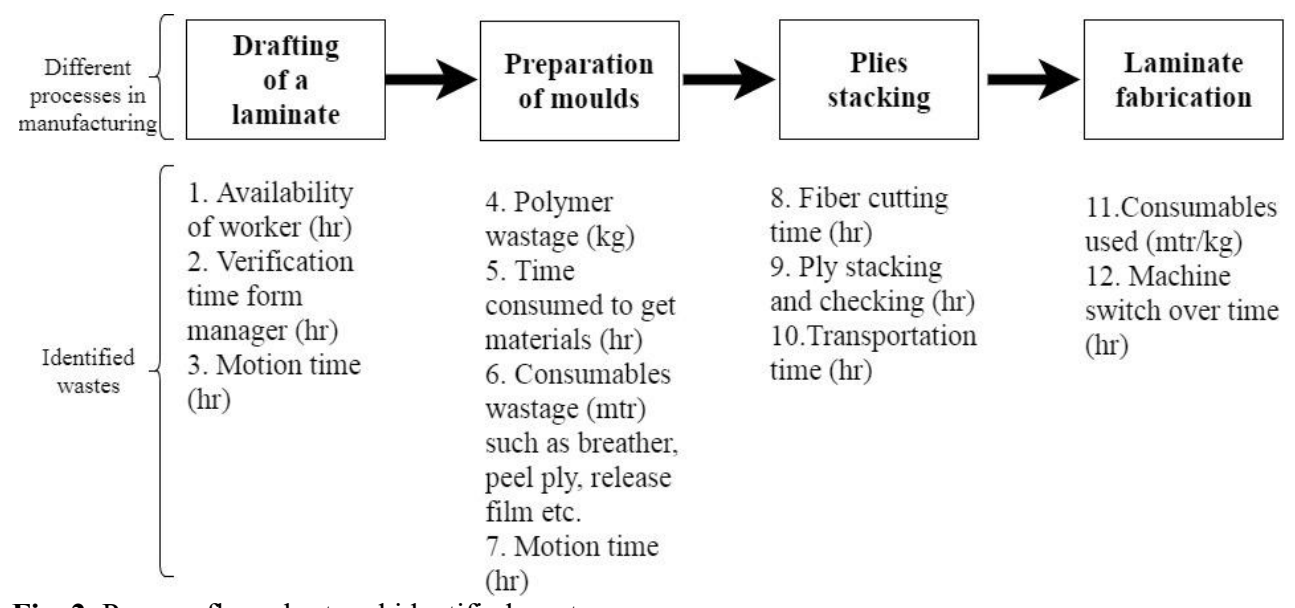

Fig. 2. Process flow chart and identified wastes.

\section{Hypothesis Testing}

The implement of lean techniques had an impact on the composite panel fabrication. By considering the availability of the worker (1) as shown in the figure 2 for production process for a time span of one-month hypotheses were drawn. After implementation, the worker has to undergo several training processes which include: training, meetings, audit and improvement etc. Table 2 shows the time, a worker available near the machine during the implementation. Later the influence on the availability of worker as well as consumables used for $5 \%$ significance was checked using paired t-test.

Hypothesis formed were:

Ha1: There is a significant influence of lean implementation on the availability of worker near the machine.

Ho1: There is no significant influence of lean implementation on the availability of worker near the machine. 


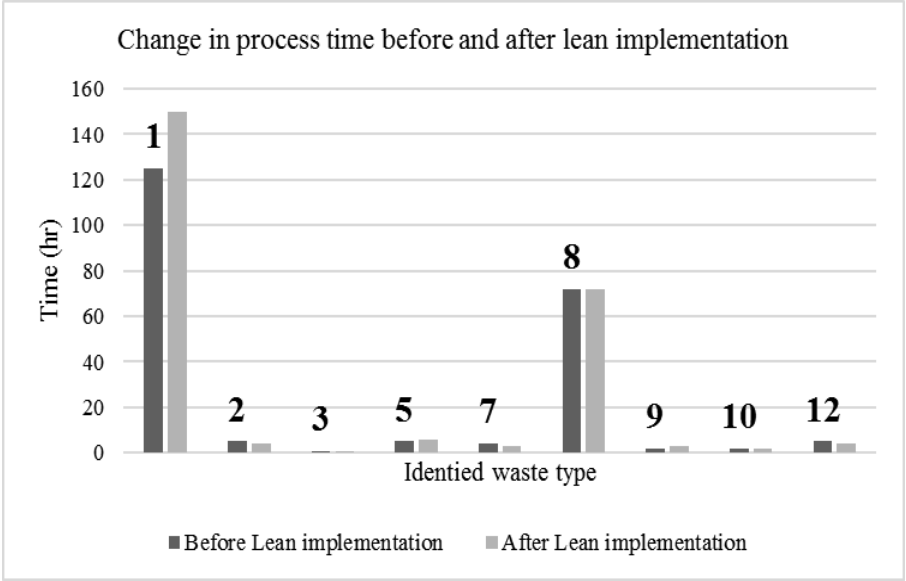

Fig. 3. Time consumed for different processes before and after implementation of lean.

Table 2. Availability of worker (hr) for a month.

\begin{tabular}{|l|l|l|l|l|l|l|l|l|l|l|l|l|l|l|l|l|l|l|l|l|l|l|}
\hline Day & $\mathbf{1}$ & $\mathbf{2}$ & $\mathbf{3}$ & $\mathbf{4}$ & $\mathbf{5}$ & $\mathbf{6}$ & $\mathbf{7}$ & $\mathbf{8}$ & $\mathbf{9}$ & $\mathbf{1 0}$ & $\mathbf{1 1}$ & $\mathbf{1 2}$ & $\mathbf{1 3}$ & $\mathbf{1 4}$ & $\mathbf{1 5}$ & $\mathbf{1 6}$ & $\mathbf{1 7}$ & $\mathbf{1 8}$ & $\mathbf{1 9}$ & $\mathbf{2 0}$ & $\mathbf{2 1}$ & $\mathbf{2 2}$ \\
\hline Before & 5 & 6 & 4 & 4 & 8 & 6 & 5 & 6 & 8 & 6 & 4 & 5 & 7 & 4 & 3 & 8 & 7 & 5 & 6 & 8 & 6 & 4 \\
\hline After & 7 & 7 & 7 & 8 & 6 & 7 & 6 & 7 & 8 & 4 & 8 & 8 & 4 & 7 & 6 & 7 & 7 & 8 & 5 & 8 & 7 & 8 \\
\hline
\end{tabular}

Later the hypothesis was further extended towards the consumables used (4, 6 and 11 of figure 2). Table 3 shows some of the consumables used before and after lean implementation.

Hypothesis formed :

Ha2: There is a significant influence of lean implementation on the consumables used.

Ho2: There is no significant influence of lean implementation on the consumables used.

Table 3. Consumables used (mtr) before and after lean implementation.

\begin{tabular}{|l|c|c|c|c|c|c|c|}
\hline Consumable & $\begin{array}{c}\text { Flow } \\
\text { mesh }\end{array}$ & Breather & Coremate & Fiber & $\begin{array}{c}\text { Poly } \\
\text { Bags }\end{array}$ & $\begin{array}{c}\text { Peel } \\
\text { ply }\end{array}$ & Sealant \\
\hline Before & 120 & 200 & 90 & 1200 & 600 & 550 & 2400 \\
\hline After & 115 & 180 & 90 & 1100 & 600 & 560 & 2500 \\
\hline
\end{tabular}

\section{Results and discussion}

Table 4 shows the results obtained from paired t-test for two different entities, where table $4(a)$ is the output for availability of worker and $4(b)$ is the output for consumables used. For a time span of one month ( 22 working days) the data were collected and the influence of the lean techniques was analyzed. It was found that, the availability of worker had a P-value of 0.019 by rejecting null hypothesis Ho1. As there was an increase in total availability of the worker by $20 \%$ after a month, the time consumed for meetings, trainings, audit etc. have not affected the aspects related to time and the lean techniques like Kanban, standardization has influenced considerably. In the case of consumables used the P-value was 0.926 which accepts null hypo thesis Ho2. Which implies the employees may need more training on lean techniques or the Kanban must be implemented in a very effective way. 
Table 4. Results of paired t-test

(a). Output for availability of worker

\begin{tabular}{|c|c|c|c|c|}
\hline \multicolumn{5}{|c|}{$\begin{array}{l}\text { Paired T-Test and Cl: before, } \\
\text { after Descriptive Statistics }\end{array}$} \\
\hline Sample & $\mathrm{N}$ & Mean & StDev & SE Mean \\
\hline before & 22 & 5.682 & 1.524 & 0.325 \\
\hline after & 22 & 6.818 & 1.220 & 0.260 \\
\hline \multicolumn{5}{|c|}{$\begin{array}{l}\text { Estimation for Paired } \\
\text { Difference }\end{array}$} \\
\hline Mean & StDev & SE M & ean & $\begin{array}{c}95 \% \mathrm{Cl} \text { for } \\
\mu \_ \text {difference }\end{array}$ \\
\hline \multicolumn{5}{|c|}{ 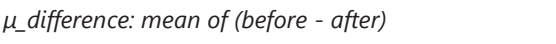 } \\
\hline \multicolumn{5}{|l|}{ Test } \\
\hline \multicolumn{3}{|c|}{ Null hypothesis } & \multicolumn{2}{|c|}{$\mathrm{H}_{0}: \mu_{-}$difference $=0$} \\
\hline \multicolumn{3}{|c|}{ Alternative hypothesis } & \multicolumn{2}{|c|}{$H_{1}: \mu \_$difference $\neq 0$} \\
\hline T-Value & P-Val & lue & & \\
\hline-2.54 & & 019 & & \\
\hline
\end{tabular}

(b). Output for consumables

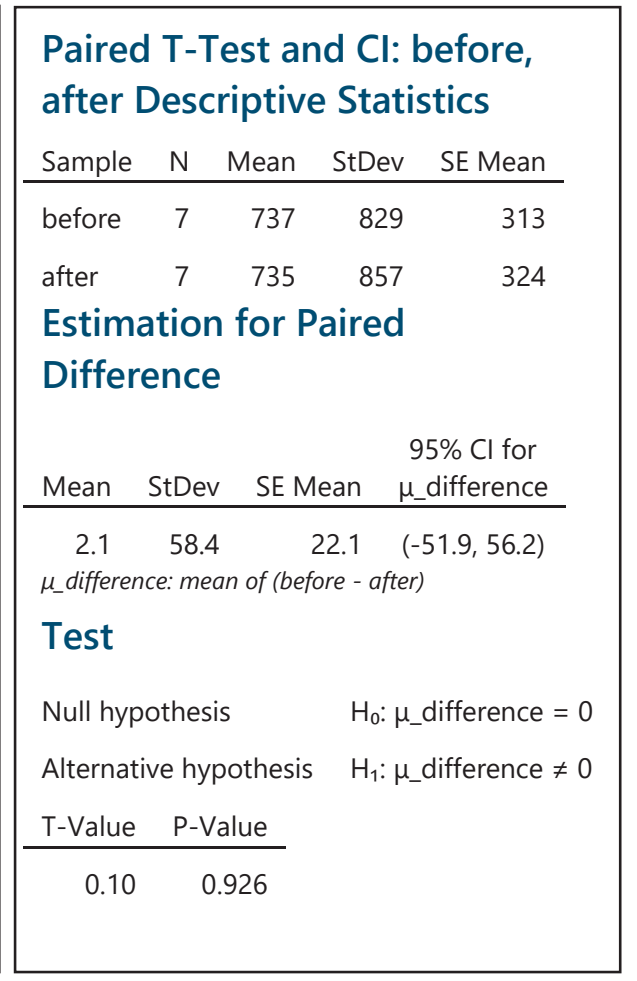

\section{Conclusions}

In a production unit, lean ideas were implemented on a small unit for a time span of one month. It is evident that mapping the process flow helps in identifying the different nonvalue adding activities in a process flow easily. Lean techniques such as Kanban and standardized operations reduces the confusions of a worker. It takes longer time for a worker to adjust to new environment, the trainings, meetings, audit etc. by pulling down the worker's availability near the machine. Finally, there is a significant influence of lean implementation on the availability of worker near the machine and there is no significant influence of lean implementation on the consumables used when considered for a month of 22 working days.

\section{References}

1. J. Rybicka, A. Tiwari, P. A. Del Campo, J. Howarth, J. of Clea. Prod., 91, 251-261 (2015).

2. M. K. Wyrwicka, B. Mrugalska, Pro. Engg., 182, 780-785 (2017).

3. G. Mouzon, M. B. Yildirim, J. Twomey, Int. J. of Prod. Res., 45(18-19), 4247-4271 (2007).

4. L. Smith, P. Ball, Int.1 J. of Pro. Econ., 140(1), 227-238 (2012).

5. F. A. Abdulmalek, J. Rajgopal, Int. J. of prod. Econ., 107(1), 223-236 (2007). 
6. C. A. Bolin, S. Smith, J. of Clea. Prod., 19(6), 620-629 (2011).

7. R. Kahhat, E. Williams, Cons. and Rec., 67, 67-74 (2012).

8. A. R. Rahani, M. Al-Ashraf, Proce. Engg., 41, 1727-1734 (2012).

9. E. Antane, D. Blumberga, Energy Procedia, 128, 358-362. (2017).

10. M. Shettar, P. Hiremath, A. Kini, S. Sharama, In Mat. Sci. For., 904, 137-141. Trans Tech Publications (2017).

11. K. W. Stier, J. of Ind. Tech. 19(4), 1-6 (2003).

12. T. L. Doolen, M. E. Hacker, J. of Mfg. syst., 24(1), 55-67 (2005).

13. S. J. Pavnaskar, J. K. Gershenson, A. B. Jambekar, Inte. Jo. of Prod. Res., 41(13), 3075-3090 (2003). 